\title{
Safety of topiramate for treating migraines.
}

Michael J. Marmura

Thomas Jefferson University

Follow this and additional works at: https://jdc.jefferson.edu/headache

Part of the Medicine and Health Sciences Commons

Let us know how access to this document benefits you

\section{Recommended Citation}

Marmura, Michael J., "Safety of topiramate for treating migraines." (2014). Department of Jefferson Headache Center papers and presentations. Paper 11.

https://jdc.jefferson.edu/headache/11

This Article is brought to you for free and open access by the Jefferson Digital Commons. The Jefferson Digital Commons is a service of Thomas Jefferson University's Center for Teaching and Learning (CTL). The Commons is a showcase for Jefferson books and journals, peer-reviewed scholarly publications, unique historical collections from the University archives, and teaching tools. The Jefferson Digital Commons allows researchers and interested readers anywhere in the world to learn about and keep up to date with Jefferson scholarship. This article has been accepted for inclusion in Department of Jefferson Headache Center papers and presentations by an authorized administrator of the Jefferson Digital Commons. For more information, please contact: JeffersonDigitalCommons@jefferson.edu. 


\title{
Safety of Topiramate for Treating Migraines
}

Michael J Marmura MD

Thomas Jefferson University

Department of Neurology, Jefferson Headache Center

Email: michael.marmura@jefferson.edu

Address: 900 Walnut Street, Suite 200

Philadelphia PA 19107

Phone: 215-955-2243

Fax: 215-955-2060

\begin{abstract}
:
Introduction: Topiramate is an effective, popular prophylactic migraine treatment that is approved for use in adults and adolescents. Due to its multiple mechanisms of action, topiramate has multiple potential safety issues, including systemic and central nervous system adverse events, that may complicate therapy. These include weight loss, metabolic acidosis, renal calculi, acute angle closure glaucoma, visual distortions, and cognitive slowing. This review highlights both common and unusual safety issues associated with topiramate use, including use in pregnancy or lactation and important drug interactions.
\end{abstract}

\section{Keywords:}

Topiramate, migraine, preventive treatment, metabolic acidosis, pallinopsia

\section{Introduction:}


Topiramate is approved by the Food and Drug Administration (FDA) for the prevention of migraine in adults $[1,2]$ and adolescents $[3,4]$. The usual dose of topiramate for migraine is 100 mg, because this dose has the best balance of efficacy and low adverse events (AEs) [5]. The doses used in clinical practice, however, may vary considerably for individual patients and disorders and may be higher for some off-label uses, such as chronic migraine or idiopathic intracranial hypertension [6].

Although topiramate was originally investigated for its potential to treat gluconeogenesis, it was subsequently found to be effective in animal models of epilepsy, and found to be effective in humans. [7] Topiramate is FDA-approved for the adjunctive treatment of partial-onset seizures, primary generalized tonic-clonic seizures, and Lennox-Gastaut syndrome in adults and children 2 years old or greater $[8,9]$. Recently the FDA approved a combination of phentermine and topiramate for the treatment of obesity in association with hypertension, type 2 diabetes, or dyslipidemia [10]. Off-label uses of topiramate in headache disorders include chronic migraine [11], trigeminal neuralgia [12], cluster headache [13], and idiopathic intracranial hypertension [14].

\section{Mechanism of Action}

Topiramate has numerous pharmacologic actions including (1) increasing gamma-aminobutyric acid (GABA) activity at GABA-A receptors; (2) inhibiting carbonic anhydrase isoenzmes II and IV; (3) blocking voltage-dependent sodium and calcium channels; (4) antagonism of the of AMPA/kainate subtype of the glutamate receptor; and (5) antagonism of 5-HT2C receptors [15].Compared to acetazolamide, tolerance to the anticonvulsant effects of topiramate is significantly longer. (Anderson RE, Chiu P, Woodbury DM, Epilepsia 1989)The exact mechanism of action that allows topiramate to be effective in migraine prophylaxis is unclear but 
may relate to inhibition of cortical spreading depression [16]. These actions contribute to multiple potential AEs with topiramate use, including both systemic and central nervous system (CNS) events. In some cases, such as antagonism of 5-HT2C receptors causing anorexia or carbonic anhydrase inhibition triggering metabolic acidosis and paresthesias, the cause of these AEs is fairly well understood. The cause of CNS AEs is less clear. In many cases the AEs are related to the dose used.

Topiramate is renally excreted, has peak levels at 2 hours and a half-life of 21 hours. Blood plasma concentration increases linearly as a function of dose. [17] Topiramate binds poorly to plasma proteins (about 15\%), meaning the drug should be dosed after dialysis in patients with renal failure.

This review will focus on common, serious, and unusual AEs associated with topiramate use, utilizing data from large clinical trials, case series, and case reports. Systemic and CNS AEs will be considered separately, as will the use of topiramate in pregnancy and lactation and drug interactions.

\section{Safety Evaluation in clinical studies and postmarketing data}

\section{Systemic AEs}

Weight loss and anorexia

Anorexia and weight loss were common AEs in topiramate clinical trials. In some cases, weight loss is desirable, and obesity is among the indications for topiramate. In the original 26-week trials, anorexia rates were $11 \%, 13 \%$ and $14 \%$, respectively, in patients taking the 50,100 and $200 \mathrm{mg}$ doses, respectively [18,19], while weight loss occurred in 5\%,10\% and $12 \%$ of patients. Those with a higher baseline weight were more likely to lose weight. Many patients reported disturbance in food taste, such as causing carbonated beverages to taste "flat" (19\% on $50 \mathrm{mg}$, 
$10 \%$ on $100 \mathrm{mg}$, and $14 \%$ on $200 \mathrm{mg}$ compared with $2 \%$ on placebo). This is also seen with other anticonvulsant drugs (i.e., acetozolamide and zonisamide).

Nausea and other gastrointestinal AEs

In clinical trials for migraine, nausea was more common in those using topiramate than in those on placebo (9\% $50 \mathrm{mg}, 13 \% 100 \mathrm{mg}$, and 14\% $200 \mathrm{mg}$ vs. 8\% placebo). Timing of drug use may affect rates of nausea: although food does not affect topiramate's effectiveness, taking it with a meal may reduce nausea $[18,19]$. Diarrhea is another common AE, with $9 \%, 11 \%$ and $11 \%$ of those in the $50 \mathrm{mg}, 100 \mathrm{mg}$ and $200 \mathrm{mg}$ groups, respectively, suffering from this condition, compared to $4 \%$ with placebo.

Paresthesias, metabolic acidosis and hypokalemia

Paresthesias are an extremely common AE in those taking topiramate. In migraine trials, topiramate users were much more likely to experience them, even at low doses $(35 \% 50 \mathrm{mg}$, $51 \% 100 \mathrm{mg}, 49 \% 200 \mathrm{mg}$ compared to $6 \%$ placebo). The cause of these paresthesias may be related to underlying metabolic acidosis. In clinical trials, lowering of bicarbonate levels occurred in $44 \%$ of those taking $200 \mathrm{mg} /$ day, 39\% taking $100 \mathrm{mg} / \mathrm{day}, 23 \%$ taking $50 \mathrm{mg} / \mathrm{day}$, and 7\% taking placebo. The incidence of abnormally low serum bicarbonate (either below 17 $\mathrm{mEq} / \mathrm{L}$ or a decrease greater than $5 \mathrm{mEq} / \mathrm{L}$ ) was $11 \%$ at $200 \mathrm{mg}, 9 \%$ at $100 \mathrm{mg}$ and $2 \%$ at $50 \mathrm{mg}$, compared with $<1 \%$ of placebo. This may cause hyperventilation, fatigue, or anorexia and in rare cases, renal failure, cardiac arrhythmias, or stupor [20]. Chronic metabolic acidosis may also decrease growth rate in children. Treatment duration does not appear to affect the prevalence of metabolic acidosis, but polymorphisms in the carbonic anhydrase type XII gene may influence the risk of its development [21]. Hypokalemia is also common, with about $7 \%$ to $10 \%$ of patients taking topiramate having low serum potassium levels [22]. In another pediatric study, potassium 
levels were significantly lower in those using topiramate (3.7 versus $4.0 \mathrm{mmol} / \mathrm{L} ; \mathrm{P}<0.03$ ) [23]. Supplemental potassium may alleviate paresthesias in patients using topiramate [24]. The package insert by Janssen Pharmaceuticals, Inc. 2009 recommends monitoring serum bicarbonate at baseline and periodically after that, although no timeframe for repeat testing is specified [25]. Patients with severe respiratory disorders or those on a ketogenic diet may be particularly susceptible; bicarbonate supplements may be useful in symptomatic patients [26]. Renal calculi

The incidence of renal calculi in migraine clinical trials was $1 \%$ at $100 \mathrm{mg}$ and $2 \%$ at $200 \mathrm{mg}$, compared with $0 \%$ for $50 \mathrm{mg}$ and placebo. The increased rate of kidney stone formation is related to the fact that topiramate causes metabolic acidosis, hypokalaemia, hyperuricemia, and hypocitraturia (a promoter of renal stone formation) [22]. Topiramate causes increased urinary $\mathrm{pH}$, bicarbonate excretion, fractional excretion of bicarbonate, and decreased urinary citrate. Those using topiramate are particularly more likely to develop calcium phosphate stones. Since the development of renal calculi takes months or years, this may be a delayed AE in topiramate users. Hydration, dietary changes, and a lower dose of topiramate may reduce this risk.

Glaucoma, including angle closure glaucoma Topiramate may rarely cause acute angle closure glaucoma as an idiosyncratic reaction. Signs and symptoms include uveal effusion, lens forward displacement, conjunctival injection, corneal edema, and increased intraocular pressure leading to vision loss. The risk of this serious reaction is highest in the first month after therapy is initiated, [27] and can cause sudden vision loss that requires urgent opthalmologic attention. Topiramate-induced glaucoma may be unilateral or bilateral, [28] and intraocular pressure may range from mildly to very highly elevated [29]. Treatment includes not covering the eye (which causes pupillary dilation), supine positioning, 
medications, and, in refractory cases, surgical procedures, such as laser peripheral iridotomy. These patients should not continue on Topiramate.

Rash and Stevens-Johnson syndrome

An erythematous rash occurred in $2 \%$ of pediatric patients in clinical trials (compared with $0 \%$ placebo) but was not reported in adult migraine trials. More severe reactions, such as erythema multiforme or Stevens-Johnson syndrome, are rare, but they are more common in patients taking multiple anti-convulsants [30].

\section{CNS AEs}

\section{Cognitive Impairment and Fatigue}

Topiramate may cause multiple cognitive AEs, which may limit therapy. In a study of topiramate for the treatment of epilepsy, treated patients had deficits of fluency, attention/concentration, processing speed, language skills, and working memory [31]. Persons with a history of psychiatric disorder are more likely to experience cognitive difficulties [32]. Verbal fluency is also impaired in persons with migraine and aura may be a risk factor for greater effects [33]. In clinical trials for migraine, memory difficulties (7\% $50 \mathrm{mg}, 7 \% 100 \mathrm{mg}$ and $11 \% 200 \mathrm{mg}$ compared with $2 \%$ placebo), attention difficulties (3\% $50 \mathrm{mg}, 6 \% 100 \mathrm{mg}$ and 10\% $200 \mathrm{mg}$ compared with $2 \%$ placebo), language problems (7\% $50 \mathrm{mg}, 6 \% 100 \mathrm{mg}$ and $7 \% 200 \mathrm{mg}$ compared with $2 \%$ placebo) and psychomotor slowing (3\% $50 \mathrm{mg}, 2 \% 100 \mathrm{mg}$ and 4\% $200 \mathrm{mg}$ compared with $1 \%$ placebo) were all greater in those using topiramate. Topiramate also is noted to increase incidence of fatigue (14\% $50 \mathrm{mg}, 15 \% 100 \mathrm{mg}$ and 19\% $200 \mathrm{mg}$ compared with 11\% placebo) and somnolence (8\% $50 \mathrm{mg}, 7 \% 100 \mathrm{mg}$ and 10\% $200 \mathrm{mg}$ compared with 5\% placebo). $[18,19]$

Pallinopsia 
Topiramate may cause visual disturbances such as pallinopsia, meaning an afterimage that persists after the visual stimulus has left. [34-36]. The effects were describing after drug approval in a series of case reports. Patients may describe visual "trails" or afterimages to describe this. The cause of pallinopsia in this case is likely related to cortical dysfunction rather than retinal pathology [37]. Topiramate may also cause other visual perceptual abnormalities, such as "Alicein-Wonderland" syndrome [34]. Visual disturbances related to topiramate appear dose-related [34] and may occur with similar medications, such as zonisamide [36]. Reducing the dose is usually necessary for symptoms to resolve.

\section{Topiramate in Pregnancy and Lactation}

The FDA recently categorized topiramate as pregnancy category D (positive evidence of human fetal risk) based on studies that demonstrate a two-fold increased risk of cleft lip, and less commonly cleft palate, in mothers using topiramate during pregnancy [38,39]. Breast feeding infants have plasma levels that are about $10 \%$ to $20 \%$ of maternal levels. No particular AEs have been noted in the infants of breastfeeding mothers using topiramate [40], but experience has been limited.

\section{Drug Interactions}

Many anticonvulsants have significant interactions with topiramate. Phenytoin, carbemazepine, valproic acid, and lamotrigine may all increase topiramate clearance and decrease levels [41]. Concomitant valproic acid use may increase the risk of hyperammonemia and encephalopathy, especially in those with mitochondrial disease [42]. Hydrochlorothiazide may increase drug levels. Topiramate should be used with caution in those taking other carbonic anhydrase inhibitors, such as zonisamide or acetazolamide, as well as metformin, which is contraindicated in those with metabolic acidosis. Topiramate may increase levels of amitriptyline and decrease 
levels of lithium, digoxin, and valproic acid. Higher doses of topiramate (over $200 \mathrm{mg} /$ day) may decrease plasma concentrations of estrogens and progestins in patients taking oral contraceptives, leading to lower efficacy rates. Topiramate can interact with CNS depressants, such as alcohol, especially in terms of cognition.

\section{Comparison of safety with other drugs}

Topiramate is one of four oral medications approved for treatment of migraine. The other medications are propranolol, timolol and divalproex sodium. Propanolol and timolol are both non-selective beta-blockers used for hypertension in addition to migraine, with fairly similar AE profiles. Divalproex sodium is approved for multiple forms of epilepsy and acute mania in bipolar disorder. Methysergide is also approved for migraine but is not currently available in the United States. A supraorbital transcranial stimulator (Cefaly) was recently approved for treatment of migraine [43] as well. In addition Onabotulinumtoxin A, given in a series of injections, is approved for the treatment of chronic migraine. Table 1 provides a comparison of significant AEs for these medications [44].

Table 1: FDA-approved medications for migraine and AEs

\begin{tabular}{|l|l|l|}
\hline Drug(s) & Common AEs & Serious AEs \\
\hline Propanolol, Timolol & Bradycardia, hypotension, & Bronchospasm, depression of \\
& weight gain, dizziness, sexual & cardiac contractility, blunting \\
dysfunction, vertigo, fatigue, & of hypoglycemia symptoms. \\
& exacerbation of peripheral & \\
& vascular symptoms & \\
\hline Divalproex sodium & Sedation, tremor, dizziness, & Hepatotoxicity, pancreatitis, \\
& weight gain, diplopia, & polycystic ovarian syndrome, \\
& thrombocytopenia. & neural tube defects \\
\hline Onabotulinumtoxin A & Injection site pain, neck & Dysphagia, diplopia \\
\hline
\end{tabular}




\begin{tabular}{|l|l|l|}
\hline & $\begin{array}{l}\text { weakness, ptosis, cosmetic } \\
\text { effects }\end{array}$ & \\
\hline Topiramate & Weight loss, nausea, & Metabolic acidosis, \\
paresthesias, renal calculi & $\begin{array}{l}\text { hypokalemia, cognitive } \\
\text { effects }\end{array}$ \\
\hline
\end{tabular}

\section{Conclusions}

Topiramate is well-established as an effective treatment for migraine, and may be a first-line migraine prophylactic agent due to its lack of weight gain, effectiveness at lower doses than those used in epilepsy, and potential cost savings. When prescribing topiramate, clinicians need to be familiar with its AEs and titrate the drug appropriately. Topiramate may take weeks or months to become effective, and the recommended titration is $25 \mathrm{mg}$ per week to an initial starting dose of $100 \mathrm{mg}$ [2]. This is in contrast to its use in epilepsy which suggests a 50 $\mathrm{mg} /$ week titration up to a minimum of $200 \mathrm{mg} /$ day [45]. In patients experiencing AEs, a slower titration may be useful to reduce discontinuation. For less serious AEs, such as nausea or paresthesias, reassurance is important, as these tend to resolve with time and the need to lower the dose may be temporary. The frequency and importance of monitoring serum bicarbonate and potassium is unclear, especially in those on a stable dose with no clear AEs. In general, clinicians should be aware of symptoms that suggest symptomatic metabolic acidosis and screen for it in those with symptoms or in those with systemic illness in general. For more problematic AEs, such as cognitive impairment, lowering the dose of topiramate or discontinuing it altogether should be considered. With skillful titration, patients may not perceive mental slowing or mood AEs, so clinicians should screen for these symptoms in patients taking higher doses. Patients 
using topiramate for extended periods of time may develop drug tolerance leading to fewer AEs, or tachyphylaxis, which may require a higher dose or render the drug ineffective.

\section{Expert Opinion:}

Topiramate is a mainstay of migraine treatment due to its efficacy and safety. Many migraine medications contribute to weight gain such as beta-blockers and antidepressants, and migraine itself may predispose to weight gain and metabolic syndrome. [46] The potential of topiramate to reduce weight may desirable. The other potential benefits of topiramate include less need for acute treatment especially those who overuse medications, more effective treatment with acute medications, lower attack severity and overall cost savings. Although migraine prevention remains underutilized \{Lipton, Silberstein $\}$, topiramate is among the most attractive and popular treatments. Topiramate is not specifically indicated for chronic migraine, unlike Onabotulinumtoxin A, but appears effective based on clinical trials. Advantages of topiramate compared to Onabotulinumtoxin A include cost and no need to perform injections on a regular basis; the disadvantage is increased AEs. Given the disparity in cost, many insurance providers will require a trial of other medication treatments such as topiramate before authorizing Onabotulinumtoxin A injections for migraine, even if the patient has chronic migraine. Topiramate's efficacy is well-established for migraine, but long-term data and outcomes are less clear. An observational study performed at our center [6]suggested that in a real-world setting topiramate dosing varies widely between patients. Patients with chronic migraine and intracranial hypertension were more likely to take topiramate at doses beyond $100 \mathrm{mg}$, and those with coexisting medical problems such as bipolar disorder, obesity, epilepsy received it more often. Only a minority of patients used topiramate for more than 1 year. Some patients discontinued due to lack of benefit or AEs, others due to migraine remission or plans for pregnancy. Ultimately 
topiramate clinicians will continue to utilize topiramate for patients with frequent or disabling migraine until more effects treatments are found with fewer AEs.

\section{Drug Summary Box:}

\begin{tabular}{|c|c|}
\hline Drug & Topiramate \\
\hline Phase & IV \\
\hline Indication & Migraine Prophylaxis \\
\hline Pharmacology & $\begin{array}{l}\text { Increases activity at GABA-A receptors; inhibits carbonic } \\
\text { anhydrase; blocks voltage-dependent sodium and calcium } \\
\text { channels; antagonist of the of AMPA/kainate subtype of the } \\
\text { glutamate receptor 5-HT2C receptors }\end{array}$ \\
\hline Route of Administration & Oral \\
\hline Chemical structure & $\begin{array}{l}\text { 2,3:4.5-Bis-O-(1-methylethylidene)-beta-D-fructopyranose } \\
\text { sulfamate }\end{array}$ \\
\hline Pivotal trials & $\begin{array}{l}\text { Brandes et al. JAMA 2004; Silberstein et al., Arch Neurol 2004; } \\
\text { Hershey et al. Headache } 2013 \text {. }\end{array}$ \\
\hline
\end{tabular}


References and recommended reading

1. SILBERSTEIN SD, BEN-MENACHEM E, SHANK RP, WIEGAND F:

Topiramate in monotherapy in epilepsy and migraine prevention. Clin Ther (2005) 27157-165.

2. STOREY JR, CALDER CS, HART DE, POTTER DL: Topiramate in migraine prevention: a double-blind, placebo-controlled study. Headache (2001) 41(10):968-975.

3. COSENTINO G, PALADINO P, MACCORA S, et al: Efficacy and safety of topiramate in migraine prophylaxis: an open controlled randomized study comparing Sincronil and topamax formulations. Panminerva Med (2013) 55(3):303-307.

4. HERSHEY AD, POWERS SW, COFFEY CS, et al: Childhood and Adolescent Migraine Prevention (CHAMP) study: a double-blinded, placebo-controlled, comparative effectiveness study of amitriptyline, topiramate, and placebo in the prevention of childhood and adolescent migraine. Headache (2013) 53(5):799-816.

5. DEATON TL, MAURO LS: Topiramate for Migraine Prophylaxis in Pediatric Patients. Ann Pharmacother. (2014)

6. MARMURA MJ, HOPKINS M, ANDREL J, et al: Electronic medical records as a research tool: evaluating topiramate use at a headache center. Headache (2010) 50(5):769-778.

7. SHANK RP, GARDOCKI JF, VAUGHT JL, et al: Topiramate: preclinical evaluation of structurally novel anticonvulsant. Epilepsia (1994) 35(2):450-460.

8. GUERRINI R: Epilepsy in children. Lancet (2006) 367(9509):499-524.

9. SACHDEO RC, GLAUSER TA, RITTER F, et al: A double-blind, randomized trial of topiramate in Lennox-Gastaut syndrome. Topiramate YL Study Group. Neurology (1999) 52(9):1882-1887.

10. GADDE KM, ALLISON DB, RYAN DH, et al: Effects of low-dose, controlled-release, phentermine plus topiramate combination on weight and associated comorbidities in overweight and obese adults (CONQUER): a randomised, placebo-controlled, phase 3 trial. Lancet (2011) 377(9774):1341-1352.

11. SILBERSTEIN SD, LIPTON RB, DODICK DW, et al: Efficacy and safety of topiramate for the treatment of chronic migraine: a randomized, double-blind, placebo-controlled trial. Headache (2007) 47(2):170-180.

12. DOMINGUES RB, KUSTER GW, AQUINO CC: Treatment of trigeminal neuralgia with low doses of topiramate. Arq Neuropsiquiatr. (2007) 65(3B):792-794. 
13. LEONE M, DODICK D, RIGAMONTI A, et al: Topiramate in cluster headache prophylaxis: an open trial. Cephalalgia (2003) 23(10):1001-1002.

14. CELEBISOY N, GOKCAY F, SIRIN H, AKYUREKLI O: Treatment of idiopathic intracranial hypertension: topiramate vs acetazolamide, an open-label study. Acta Neurol Scand. (2007) 116(5):322-327.

15. SHANK RP, GARDOCKI JF, STREETER AJ, MARYANOFF B: An overview of the preclinical aspects of topiramate: pharmacology, pharmacokinetics, and mechanism of action. Epilepsia (2000) 41 (S1):S3-S9

16. AYATA C, JIN H, KUDO C, DALKARA T, MOSKOWITZ MA: Suppression of cortical spreading depression in migraine prophylaxis. Ann Neurol (2006) 59(4):652-661.

17. JOHANNESSEN SI: Pharmacokinetics and interaction profile of topiramate: review and comparison with other newer antiepileptic drugs. Epilepsia (1997) 38 Suppl 1S18-S23

18. BRANDES JL, SAPER JR, DIAMOND M, et al: Topiramate for migraine prevention: a randomized controlled trial . JAMA (2004) 291(8):965-973.

19. SILBERSTEIN SD, NETO W, SCHMITT J, JACOBS D: Topiramate in the prevention of migraine headache: a randomized, double-blind, placebo-controlled, multiple-dose study. For the MIGR-001 Study Group. Arch Neurol (2004) 61490-495.

20. BORRON SW, WOOLARD R, WATTS S: Fatal heat stroke associated with topiramate therapy. Am. J Emerg. Med (2013) 31(12):1720-1726.

21. MIRZA NS, ALFIREVIC A, JORGENSEN A, MARSON AG, PIRMOHAMED M: Metabolic acidosis with topiramate and zonisamide: an assessment of its severity and predictors. Pharmacogenet. Genomics (2011) 21(5):297-302.

22. DELL'ORTO VG, BELOTTI EA, GOEGGEL-SIMONETTI B, et al: Metabolic disturbances and renal stone promotion on treatment with topiramate: a systematic review. Br J Clin Pharmacol (2013)

23. BELOTTI EA, TADDEO I, RAGAZZI M, et al: Chronic impact of topiramate on acid-base balance and potassium in childhood. Eur J Paediatr. Neurol (2010) 14(5):445-448.

24. SILBERSTEIN SD: Control of topiramate-induced paresthesias with supplemental potassium (Letter). Headache (2002) 4285

25. BRANDES JL: Practical use of topiramate for migraine prevention. Headache (2005) 45 Suppl 1S66S73

26. TAKEOKA M, RIVIELLO JJ, JR., PFEIFER H, THIELE EA: Concomitant treatment with topiramate and ketogenic diet in pediatric epilepsy. Epilepsia (2002) 43(9):1072-1075. 
27. HO JD, KELLER JJ, TSAI CY, et al: Topiramate use and the risk of glaucoma development: a population-based follow-up study. Am. J Ophthalmol. (2013) 155(2):336-341.

28. QUAGLIATO LB, BARELLA K, ABREU NETO JM, QUAGLIATO EM: Topiramate-associated acute, bilateral, angle-closure glaucoma: case report. Arq Bras. Oftalmol. (2013) 76(1):48-49.

29. VAN IC, MAVRAKANAS N, SCHUTZ JS, SHAARAWY T: Topiramate-induced acute bilateral angle closure and myopia: pathophysiology and treatment controversies. Eur J Ophthalmol. (2011) 21(4):404-409.

30. ARIF H, BUCHSBAUM R, WEINTRAUB D, et al: Comparison and predictors of rash associated with 15 antiepileptic drugs. Neurology (2007) 68(20):1701-1709.

31. LEE S, SZIKLAS V, ANDERMANN F, et al: The effects of adjunctive topiramate on cognitive function in patients with epilepsy. Epilepsia (2003) 44(3):339-347.

32. KANNER AM: Depression in epilepsy: a frequently neglected multifaceted disorder. Epilepsy Behav (2003) 4 Suppl 411-19.

33. ROMIGI A, CERVELLINO A, MARCIANI MG, et al: Cognitive and psychiatric effects of topiramate monotherapy in migraine treatment: an open study. Eur J Neurol (2008) 15(2):190-195.

34. EVANS RW: Reversible palinopsia and the Alice in Wonderland syndrome associated with topiramate use in migraineurs. Headache (2006) 46(5):815-818.

35. FONTENELLE LF: Topiramate-induced palinopsia. J Neuropsychiatry Clin Neurosci (2008) 20(2):249250.

36. SIERRA-HIDALGO F, DE PABLO-FERNANDEZ E: Palinopsia induced by topiramate and zonisamide in a patient with migraine. Clin Neuropharmacol. (2013) 36(2):63-64.

37. HAYASHI R, SHIMIZU S, WATANABE R, KATSUMATA Y, MIMURA M: Palinopsia and perilesional hyperperfusion following subcortical hemorrhage. Acta Neurol Scand. (2002) 105(3):228-231.

38. HUNT S, RUSSELL A, SMITHSON WH, et al: Topiramate in pregnancy: preliminary experience from the UK Epilepsy and Pregnancy Register. Neurology (2008) 71(4):272-276.

39. MARGULIS AV, MITCHELL AA, GILBOA SM, et al: Use of topiramate in pregnancy and risk of oral clefts. Am. J Obstet Gynecol (2012) 207(5):405-407.

40. OHMAN I, VITOLS S, LUEF G, SODERFELDT B, TOMSON T: Topiramate kinetics during delivery, lactation, and in the neonate: preliminary observations. Epilepsia (2002) 43(10):1157-1160.

41. JOHANNESSEN SI, LANDMARK CJ: Antiepileptic drug interactions - principles and clinical implications. Curr Neuropharmacol. (2010) 8(3):254-267. 
42. HAMER HM, KNAKE S, SCHOMBURG U, ROSENOW F: Valproate-induced hyperammonemic encephalopathy in the presence of topiramate. Neurology (2000) 54(1):230-232.

43. SCHOENEN J, VANDERSMISSEN B, JEANGETTE $S$, et al: Migraine prevention with a supraorbital transcutaneous stimulator: a randomized controlled trial. Neurology (2013) 80(8):697-704.

44. Silberstein SD, Marmura MJ. Essential neuropharmacology: the prescriber's guide. In: Essential neuropharmacology: the prescriber's guide. New York: Cambridge University press; 2010.

45. FAUGHT E, WILDER BJ, RAMSAY RE, et al: Topiramate placebo-controlled dose-ranging trial in refractory partial epilepsy using 200-, 400-, and 600-mg daily dosages. Topiramate YD Study Group. Neurology (1996) 46(6):1684-1690.

46. SACHDEV A, MARMURA MJ: Metabolic syndrome and migraine. Front Neuro/ (2012) 3161 